\title{
28 Research Soure \\ Imbalance of circulating Tfh/Tfr cells in patients with Parkinson's disease
}

\section{Xiuzhen Zhao}

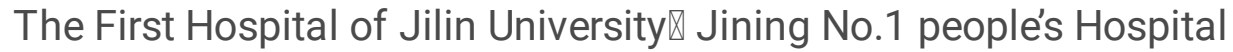

\section{Tao Jin}

The First Hospital of Jilin University

\section{Chao Zheng}

The First Hospital of Jilin University

\section{Di Ma}

The First Hospital of Jilin University

\section{Ying Zhang ( $\square$ zhang_ying99@jlu.edu.cn )}

The First Hospital of Jilin University https://orcid.org/0000-0002-4448-2051

\section{Research}

Keywords: Parkinson's disease, follicular helper T cell, follicular regulatory T cell, pathogenesis, immune inflammation

Posted Date: May 28th, 2020

DOl: https://doi.org/10.21203/rs.3.rs-28078/v1

License: (c) (i) This work is licensed under a Creative Commons Attribution 4.0 International License. Read Full License 


\section{Abstract}

Background: Follicular helper $\mathrm{T}(\mathrm{Tfh})$ cells and follicular regulatory $\mathrm{T}(\mathrm{Tfr})$ cells are essential for $\mathrm{B}$ cell differentiation, germinal center formation, and humoral immune responses. Immunity and inflammation have been thought to be involved in Parkinson's disease (PD). In this study, we aimed to identify whether circulating Tfh and $\operatorname{Tfr}$ (cTfh and cTfr) cells contribute to PD.

Methods: Thirty-nine PD patients and 26 health controls (HCs) were enrolled. The numbers of cTfh $\left(\mathrm{CD} 4^{+} \mathrm{CXCR} 5^{+} \mathrm{PD}-1^{+}\right)$cells and $\mathrm{CTfr}\left(\mathrm{CD} 4^{+} \mathrm{CXCR} 5^{+} \mathrm{CD} 25^{\text {hi }} \mathrm{CD} 127^{\text {low }}\right)$ cells were analyzed via flow cytometry. The serum concentrations of interleukin (IL)-4, IL-10, IL-21, and transforming growth factor (TGF) $-\beta$ were examined by cytometric bead array.

Results: The percentage of cTfh cells among $\mathrm{CD} 4^{+} \mathrm{T}$ cells in PD patients was significantly higher than that in $\mathrm{HCs}$ [3.68\% (2.64\%-5.70\%) vs $1.94 \%(1.32 \%-2.99 \%), \mathrm{P}<0.001]$, while the percentage of cTfr cells among $\mathrm{CD} 4^{+} \mathrm{T}$ cells in PD patients was slight decreased but without significance [1.05\% $(0.62 \%-1.54 \%)$ vs $1.3 \%(0.63 \%-1.90 \%), P>0.05]$. The percentage of $C D 19^{+} B$ cells in peripheral blood mononuclear cells was significantly lower in PD patients than in HCs [5.35\% (4.13\%-9.38\%) vs $8.68 \%(5.61 \%-12.93 \%)$, $P=0.014]$. The serum concentrations of IL-4, IL-10, IL-21, and TGF- $\beta$ in PD patients did not differ significantly from those in HCs $(P>0.05)$. However, significant positive correlations were found for the serum concentration of IL-21 with $\mathrm{H}-\mathrm{Y}$ stage $(r=0.356, \mathrm{P}=0.026)$ and UPDRS-III score $(r=0.347, \mathrm{P}=0.030)$.

Conclusions: These results indicate that an imbalance of cTfh and cTfr cells may be involved in the chronic progression of PD, and IL-21 may be a biomarker for monitoring the severity of this disease.

\section{Background}

Parkinson's disease (PD), also known as tremor paralysis, is a common neurological degenerative disease in the elderly. The basic pathological changes of PD are the degeneration and loss of dopaminergic neurons in brain substantia nigra. Eosinophilic inclusion bodies appear in the remaining neurons and are called Lewy bodies. Alpha-synuclein (a-syn) is known to be the main structural component of the Lewy bodies [1]. In 2003, Braak and colleagues proposed the Braak staging system for sporadic PD, which divided the pathological changes of PD into six stages according to the pathological diffusion sequence of a-syn [2]. This theory provided an anatomical basis for the motor and non-motor symptoms of PD. Some researchers believed that a-syn accumulates in neurons and propagates in a prion-like manner, which is involved in the aggravation of PD [3]. However, the detailed mechanism remains unclear.

In 1988, McGeer et al. found that activated microglia were present around the degenerative and necrotic dopaminergic neurons in the brain of PD patients on autopsy [4]. Since then, the immune system and inflammation reaction have been considered to play roles in the pathogenesis of PD. Chen et al. injected the IgG extracted from the serum of PD patients into the right substantia nigra area of adult rats and 
observed obvious dopaminergic neuron loss and microglia infiltration in the injected side compared to the uninjected side [5]. This suggests that abnormal pathogenic antibodies may be present in PD patients. Combined with the Braak staging theory, we speculate that abnormally aggregated a-syn may act as an autoantigen to continuously activate the body's autoimmune response, resulting in an immune stress state in the body, which may be one reason for the chronic and persistent progression of PD.

Follicular helper T (Tfh) cells, a special CD4 ${ }^{+}$T-cell subset, were discovered by Schaerli et al. in 2000. They are derived from the tonsil tissue and localized in the lymphoid follicles. Tfh cells are essential in the differentiation of B cells into high-affinity plasma cells, the formation of germinal centers, and immunoglobulin class switching. They can also maintain the body's long-term humoral immune response [6-8]. In contrast, follicular regulatory $\mathrm{T}$ ( $\mathrm{Tfr}$ ) cells, which were recently defined, can suppress the reactions of Tfh cells and $B$ cells in the germinal center and inhibit the sustained immune activation state $[9,10]$. The balance between Tfh and Tfr cells plays an important role in maintaining the body's immune homeostasis. Tfh cells and Tfr cells in the peripheral circulation express the same surface molecules as the respective cell types in lymphoid tissues and have the same functional characteristics. Imbalance of circulating Tfh and $\operatorname{Tfr}$ (cTfh and $\mathrm{cTfr}$ ) cells has been shown in autoimmune diseases such as rheumatoid arthritis [11], myasthenia gravis [12], ulcerative colitis [13], and renal allograft dysfunction [14]. To date, few studies have investigated the balance of cTfh and cTfr cells in PD.

In the present study, we measured the levels of Tfh cells and Tfr cells as well as the related cytokines in PD patients. Our results suggest that changes in relative cTfh and cTfr cell numbers may cause an immune responsive state in PD patients, contributing to the pathogenesis of PD.

\section{Materials And Methods}

\section{Patients}

The study was approved by the ethics committee of the First Hospital of Jilin University. Fasting blood samples were obtained from PD patients $(n=39)$ and age- and gender-matched healthy controls (HCs, $\mathrm{n}=26$ ). All subjects provided informed consent according to the Declaration of Helsinki. The enrolled PD patients were diagnosed and treated in the Department of Neurology of the First Hospital of Jilin University during 2017-2018. The disease was evaluated according to the clinical diagnostic criteria for PD put forth by the Movement Disorders Association (MDS) in 2015 [15]. The exclusion criteria included recent infection symptoms or suspected infection; usage of antibiotics, hormones and immunosuppressants in the past 3 months; autoimmune diseases (such as systemic lupus erythematosus, rheumatoid arthritis, Sjogren's syndrome, myasthenia gravis, multiple sclerosis, etc.); severe digestive, circulatory, endocrine, and hematological disorders; and familial PD. The third part of the Unified Parkinson's Disease Rating Scale (UPDRS-III) [16] and modified Hoehn-Yahr stage scale (H-Y stage) [17] were used to evaluate the motor symptoms and clinical staging of patients. The Non-Motor Symptoms Scale (NMSS) was used to assess the severity of patients' nonmotor symptoms [18]. According to $\mathrm{H}-\mathrm{Y}$ stage, PD patients were divided into two subgroups: stage $\mathrm{I}-\mathrm{II}$ is early PD, and more than 
stage II is defined as middle-advanced PD. The demographic and clinical characteristics of the study participants are summarized in Table. 1.

\section{Cell isolation and flow cytometry}

Heparin-anticoagulated whole blood samples were collected to determine the T-cell subsets. Peripheral blood mononuclear cells (PBMCs) were separated within $4 \mathrm{~h}$ by density gradient centrifugation with red blood cell lysis buffer (Solarbio, China). Aliquots of $1 \times 10^{6}$ PBMCs were re-suspended in PBS and stained with antibodies at room temperature for $30 \mathrm{~min}$. The antibodies included V500-conjugated anti-CD4 antibody, Alexa Fluor 647-conjugated anti-CXCR5 antibody, PerCP-Cy5.5-conjugated anti-PD-1 antibody, FITC-conjugated anti-CD25 antibody, V451-conjugated anti-CD127 antibody, and PE-conjugated antiCD19 antibody. After staining, PBMCs were washed three times and analyzed using a BD FACSAria ${ }^{\mathrm{TM}}$ II Cell Sorter (BD, USA). The gating strategy was first based on the forward/side scatter, followed by CD 4 and CXCR5 positivity. After collection of $\mathrm{CD} 4^{+} \mathrm{CXCR} 5^{+} \mathrm{T}$ cells, the frequencies of $\mathrm{CTfh}\left(\mathrm{CD} 4^{+} \mathrm{CXCR} 5^{+} \mathrm{PD}-\right.$ $\left.1^{+}\right)$and $\mathrm{CTfr}\left(\mathrm{CD} 4^{+} \mathrm{CXCR}^{+} \mathrm{CD} 25^{\text {hi }} \mathrm{CD} 127^{\text {low }}\right)$ cells were calculated based on PD-1 and CD25/CD127 expression, respectively. The percentage of B cells (CD19+) was also calculated (Fig.1).

\section{Measurement of serum IL-4, IL-10, IL-21 and TGF- $\beta$ concentrations}

Serum samples were collected and stored at $-80^{\circ} \mathrm{C}$ until analysis. The serum concentrations of IL-4, IL-10, IL-21, and TGF- $\beta$ were determined by cytometric bead array (CBA) with human CBA Flex Sets, according to the manufacturer's protocols (BD, USA).

\section{Statistical analysis}

All data were analyzed using SPSS 22.0 statistical software (SPSS, Inc., USA). The measurement data were tested for normality. For data with a normal distribution, Values are expressed as mean \pm standard deviation, and two independent sample t tests were performed for comparisons. For data with a nonnormal distribution, values are expressed as the median (interquartile range), and the Mann-Whitney $\mathrm{U}$ test was performed for comparisons. Spearman correlation analysis was performed to identify correlations between variables. $\mathrm{P}<0.05$ was considered statistically significant.

\section{Results}

\section{Characteristics of enrolled subjects}

A total of 39 patients with PD and 26 age- and gender-matched HCs were recruited. The demographic and clinical characteristics of the subjects are described in Table 1. There were no significant differences in age, gender, or body mass index (BMI) between the PD and HC groups. Compared to the patients in the early PD group, patients in the middle-advanced PD group had a significantly increased disease duration, $\mathrm{H}-\mathrm{Y}$ stage, UPDRS-III score, and NMSS score $(\mathrm{P}<0.05)$. 
Table 1 Demographic and clinical characteristics of enrolled PD patients and HCs.

\begin{tabular}{|c|c|c|}
\hline HCs & PD patients & $\begin{array}{l}\text { Early PD } \\
\text { patients }\end{array}$ \\
\hline
\end{tabular}

\begin{tabular}{lllll}
\hline Number & 26 & 39 & 28 & 11 \\
\hline Age (years) & $60.77 \pm 6.77$ & $61.49 \pm 5.79$ & $61.71 \pm 5.98$ & $60.91 \pm 5.47$ \\
\hline Gender (male/female) & $13 / 13$ & $20 / 19$ & $16 / 12$ & $4 / 7$ \\
\hline BMI $\left(\mathrm{kg} / \mathrm{m}^{2}\right)$ & $24.09 \pm 2.34$ & $23.92 \pm 2.96$ & $23.84 \pm 2.59$ & $24.10 \pm 3.88$ \\
\hline $\begin{array}{l}\text { Disease duration } \\
\text { (years) }\end{array}$ & $\square$ & $3(1-8)$ & $3(1-6)$ & $8(3-10)^{*}$ \\
\hline Hoehn-Yahr stage & $\square$ & $1.5(1-3)$ & $1.25(1-1.5)$ & $3(3-3)^{*}$ \\
\hline UPDRS-III score & $\square$ & $19(14-28)$ & $16(12-20)$ & $35(26-47)^{*}$ \\
\hline NMSS score & $\square$ & $48.18 \pm 25.44$ & $42.79 \pm 20.43$ & $61.91 \pm 32.29^{*}$
\end{tabular}

Data are shown as mean \pm standard deviation or median (interquartile range). BMI, body mass index. ${ }^{*} \mathrm{P}<0.05$ between the early PD and middle-advanced PD groups.

Altered frequencies of cTfh, cTfr and B cells in PD patients

According to the expression patterns of PD- 1 and CD25/CD127, CD $4^{+} \mathrm{CXCR} 5^{+}$cells in the peripheral blood

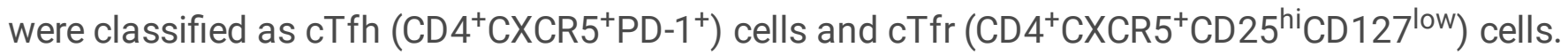

Compared to that in $\mathrm{HCs}$, the percentage of $\mathrm{CD} 4^{+} \mathrm{T}$ cells among lymphocytes was slightly lower in $\mathrm{PD}$ patients, but this difference was without statistical difference $(32.60 \%(27.60 \%-41.95 \%)$ vs $35.65 \%$ (26.50\%-48.4\%), $P>0.05$, Fig. 2A). The percentage of $\mathrm{cTfh}$ cells among $\mathrm{CD} 4^{+} \mathrm{T}$ cells was significantly higher in PD patients than in HCs (3.68\% (2.64\%-5.70\%) vs 1.94\% (1.32\%-2.99\%), P<0.0001, Fig. 2B). However, there was no significant difference between the early PD group and middle-advanced PD group $\left(P>0.05\right.$, Fig. 2E). The percentage of $c T f r$ cells among $C D 4^{+} T$ cells appeared to be lower in PD patients than in HCs, but the difference was without significant difference $(1.05 \%(0.62 \%-1.54 \%)$ vs $1.3 \%(0.63 \%-$ $1.90 \%)$, P>0.05, Fig. 2C).

In our study, we also found that the percentage of CD19+ $\mathrm{B}$ cells among PBMCs was significantly lower in PD patients than in $\mathrm{HCs}(5.35 \%(4.13 \%-9.38 \%)$ vs $8.68 \%$ (5.61\%-12.93\%), P=0.014, Fig. 2D). However, similar to cTfh cells, no significant difference was found between the early PD group and middleadvanced PD group ( $P>0.05$, Fig. 2F).

Correlations of cTfh percentage, cTfr percentage, and cTfh/cTfr ratio with clinical symptoms 
No significant correlations were found between the percentages of cTfh cells or cTfr cells in PD patients with patients' age, disease duration, disease severity (UPDRS-III score), or nonmotor symptoms (NMSS) $(P>0.05$, Fig. 3 A-D). However, the cTfh/cTfr ratio in PD patients was significantly higher than that in HCs $(P<0.0001$, Fig. 3E). Although the correlation of the cTfh/cTfr ratio and NMSS in PD patients showed no statistical significance $(P=0.058$, Fig. $3 F)$, a significant negative correlation was observed after adjustment to remove an abnormal value $(P=0.016)$.

Serum concentrations of IL-4, IL-10, IL-21, and TGF- $\beta$ in PD patients

CBA measurements showed that the serum concentrations of IL-4, IL-10, IL-21, and TGF- $\beta$ did not differ significantly between PD patients and HCs ( $P>0.05$, Fig. 4A-D).

\section{Correlations of serum IL-4, IL-10, IL-21, and TGF- $\beta$ concentrations with clinical symptoms}

We also performed correlation analyses to identify significant associations between serum IL-4, IL-10, IL21 , and TGF- $\beta$ concentrations and clinical symptoms. The results showed no significant correlations between serum IL-4, IL-10, and TGF- $\beta$ concentrations in PD patients and patients' age, disease duration, disease severity (UPDRS-III score), and nonmotor symptoms (NMSS) ( $P>0.05)$. However, significant positive correlations were found between the serum IL-21 concentration and $\mathrm{H}-\mathrm{Y}$ stage $(r=0.356, P=0.026$, Fig. 4E) as well as UPDRS-III score ( $r=0.347, \mathrm{P}=0.030$, Fig. 4F).

\section{Discussion}

As a common neurological degenerative disease in the elderly, PD is a progressive disorder that affects movement. At present, the pathogenesis of PD remains incompletely understood. Mitochondrial dysfunction [19], cell apoptosis [20], ubiquitin-proteasome disorders[21], and oxidative stress [22] are thought to participate in PD pathogenesis. Additionally, immunity and inflammation have been proposed to be involved in PD [23]. Chen et al. found that the proportion of CD4+ T cells among lymphocytes in patients with PD is decreased. Th1 cells and Th17 cells are increased significantly in the PD group, and the proportions of Th2 cells and regulatory T cells are decreased significantly [24]. Studies have shown that the number of $\mathrm{B}$ lymphocytes in the peripheral blood of patients with PD is also decreased[25]. Cytokines such as IL-2, IL-4, IL-10, IL-6, TNF-a, and IFN- $y$ are increased in the peripheral blood of patients with PD [26]. In addition, Kim et al. showed that IL-10 concentrations are positively correlated with nonmotor symptoms in PD [27]. Up to now, studies on inflammation in PD have mainly focused on the detection of pro-inflammatory cytokines, such as TNF- $a$, IL- $1 \beta$, IL-6, and IFN- $\gamma$, and anti-inflammatory cytokines, such as IL-10 and TGF- $\beta$, in the cerebrospinal fluid and peripheral blood of PD patients. Research on immunity in PD has mostly focused on the activation of microglia and astrocytes, and the imbalance of B lymphocytes and T lymphocytes and their subpopulations [28]. Little research has been carried out to elucidate the role of humoral immunity in PD. The present study, to our knowledge, is the first to investigate the humoral immunity in PD by measuring the levels of cTfh and cTfr cells, and the related cytokines in PD patients. We found that the percentage of cTfh cells was increased and the 
percentage of cTfr cells among $\mathrm{CD} 4^{+} \mathrm{T}$ cells was decreased in PD patients compared to HCs, further analysis showed that the ratio of cTfh/cTfr was elevated, which indicating an activated humoral response state in PD. Furthermore, the concentration of serum IL-21, which is an effector molecular of cTfh cells, was positively correlated with the $\mathrm{H}-\mathrm{Y}$ stage and UPDRS-III score in PD patients, suggesting that IL-21 may be used as a marker to assess the severity of the disease.

Tfh cells can promote the generation of germinal centers, promote differentiation of B cells into plasma cells, and produce antibodies, which play an important role in humoral immune responses. Peripheral circulating Tfh cells express the same surface molecules as Tfh cells in lymphoid tissue and have the same function [29-31]. In this study, cTfh cells were detected based on the CD $4^{+}$CXCR5 ${ }^{+} P D-1^{+}$expression pattern. Among these markers, PD-1 is a key phenotypic marker of Tfh cells. Due to the wide distribution of PD-1 ligands in the body, PD-1 plays an important role in regulating the immune response [32, 33]. In addition, PD-1 on the surface of Tfh cells can also regulate the survival and affinity maturation of memory B cells and plasma cells at the germinal center and promote IL-21 secretion, leading to the production of more antibodies [34]. Circulating Tfh cells were shown to be increased in PD patients compared to HCs, suggesting an imbalance of the humoral immune response in PD. It is speculated that this may be due to the continuous a-syn or other pathogenic factors stimulation in PD patients, which induces long-term activation of humoral immunity. Although no significant correlations were found between the percentage of cTfh cells and age, disease course, or disease severity (UPDRS-III) in the PD patients, studies with a large sample are needed for further verification of these results.

Tfr cells exert opposing functions to Tfh cells, inhibiting the formation of germinal centers and the production of antibodies. Although the mechanism is not clear, CTLA-4 and cytokines (IL-21, IL-4, IL-10, and TGF- $\beta$ ) are thought to be involved in the regulatory function of Tfr cells [35-38]. The $\mathrm{CD} 4^{+} \mathrm{CXCR} 5^{+} \mathrm{CD} 25^{\mathrm{hi}} \mathrm{CD} 127^{\text {low }}$ expression pattern was used to identify cTfh cells. Compared to that in $\mathrm{HCs}$, the percentage of cTfr cells in PD patients in this study was not significantly altered, but showed a slightly decreasing trend, which suggests a possible decrease in cTfr cells in PD. A reduction of cTfr cells may lead to continuous activation of the humoral immune response, which may be related to the chronic progressive course of PD. The significantly increased cTfh/cTfr ratio in PD patients also confirms the presence of a persistent abnormal immune response in the progressive course of PD.

Consistent with the results of previous studies [25], the proportion of $\mathrm{CD} 19^{+} \mathrm{B}$ cells in PD patients was significantly reduced compared with that in HCs. The related mechanism is not clear; it may be related to the active inflammatory response and the activation of immune cells in PD patients, or to the inhibitory regulation of Tfr cells. The limitation of our study is that we did not measure the content of plasma cells in peripheral blood.

IL-4 and IL-21 are characteristic cytokines of Tfh cells. In this study, the serum concentrations of IL-4 and IL-21 were not significantly different between the PD patients and HCs. However, the serum concentration of serum IL-21 was positively correlated with the severity of the disease in patients with PD. Previous studies have also shown that IL-21 is associated with the severity of diseases such as systemic lupus 
erythematosus, rheumatoid arthritis, type 1 diabetes, and Sjogren's syndrome [39]. Thus, IL-21 may represent a useful biological indicator for monitoring the severity of PD as well as a new target for treatment.

\section{Conclusions}

In summary, the percentage of cTfh cells was significantly increased in PD patients, and the percentage of cTfr cells showed a significant decreasing trend, the cTfh/cTfr ratio was further increased, which suggested a continuously activated humoral response state and may be involved in the chronic progression mechanism of PD. The serum IL-21 concentration was positively correlated with the UPDRSIII score and $\mathrm{H}-\mathrm{Y}$ stage in PD patients, which suggests that IL-21 may be a biomarker for monitoring the severity of PD and a possible target for disease intervention.

\section{Declarations}

\section{Acknowledgements}

Not applicable.

\section{Authors' contributions}

ZX, JT and ZY designed experiments and analyzed data. All the authors collected data and contributed to analyze the results. ZY revised the manuscript. All authors read and approved the final manuscript.

\section{Funding}

This work was supported by Natural Science Foundation of China (No. 81974194) (to Ying Zhang), by Jilin Province Health and Family Planning Commission (No. 2018J045) (to Ying Zhang).

\section{Availability of data and materials}

All data generated and/or analyzed during this study are included in this published article and additional information is available upon request.

\section{Ethics approval and consent to participate}

The study was approved by the ethics committee of the First Hospital of Jilin University. All subjects provided informed consent for blood donation.

\section{Consent for publication}

Not applicable.

\section{Competing interests}


All authors declared no competing interests in this study.

\section{References}

1. Kalia LV, Lang AE. Parkinson's disease. Lancet.2015;386:896-912.

2. Braak H, Del Tredici K, Rub U, de Vos RA, Jansen Steur EN, Braak E. Staging of brain pathology related to sporadic Parkinson's disease. Neurobiol Aging.2003;24:197-211.

3. Steiner JA, Quansah E, Brundin P. The concept of alpha-synuclein as a prion-like protein: ten years after. Cell Tissue Res.2018;373:161-73.

4. McGeer PL, Itagaki S, Boyes BE, McGeer EG. Reactive microglia are positive for HLA-DR in the substantia nigra of Parkinson's and Alzheimer's disease brains. Neurology.1988;38:1285-91.

5. Chen S, Le WD, Xie WJ, Alexianu ME, Engelhardt JI, Siklos L, Appel SH. Experimental destruction of substantia nigra initiated by Parkinson disease immunoglobulins. Arch Neurol.1998;55:1075-80.

6. Schaerli P, Willimann K, Lang AB, Lipp M, Loetscher P, Moser B. CXC chemokine receptor 5 expression defines follicular homing T cells with B cell helper function. J Exp Med.2000;192:1553-62.

7. Breitfeld D, OhI L, Kremmer E, Ellwart J, Sallusto F, Lipp M, Forster R. Follicular B helper T cells express $C X C$ chemokine receptor 5 , localize to $B$ cell follicles, and support immunoglobulin production. J Exp Med.2000;192:1545-52.

8. Kim CH, Rott LS, Clark-Lewis I, Campbell DJ, Wu L, Butcher EC. Subspecialization of CXCR5+ T cells: $B$ helper activity is focused in a germinal center-localized subset of CXCR5+ T cells. $J$ Exp Med.2001;193:1373-81.

9. Wollenberg I, Agua-Doce A, Hernandez A, Almeida C, Oliveira VG, Faro J, Graca L. Regulation of the germinal center reaction by Foxp3+ follicular regulatory T cells. J Immunol.2011;187:4553-60.

10. Sage PT, Sharpe AH. T follicular regulatory cells in the regulation of $B$ cell responses. Trends Immunol.2015;36:410-8.

11. Wang X, Yang C, Xu F, Qi L, Wang J, Yang P. Imbalance of circulating Tfr/Tfh ratio in patients with rheumatoid arthritis. Clin Exp Med. 2019;19:55-64.

12. Wen Y, Yang B, Lu J, Zhang J, Yang H, Li J. Imbalance of circulating CD4(+)CXCR5(+)FOXP3(+) Tfrlike cells and CD4(+)CXCR5(+)FOXP3(-) Tfh-like cells in myasthenia gravis. Neurosci Lett.2016;630:176-82.

13. Wang X, Zhu Y, Zhang M, Hou J, Wang H, Jiang Y, Wang H, Gao P. The shifted balance between circulating follicular regulatory $\mathrm{T}$ cells and follicular helper $\mathrm{T}$ cells in patients with ulcerative colitis. Clin Sci (Lond).2017;131:2933-45.

14. Yan L, Li Y, Li Y, Wu X, Wang X, Wang L, Shi Y, Tang J. Increased circulating Tfh to Tfr ratio in chronic renal allograft dysfunction: a pilot study. BMC Immunol.2019;20:26.

15. Postuma RB, Berg D, Stern M, Poewe W, Olanow CW, Oertel W, Obeso J, Marek K, Litvan I, Lang AE et al. MDS clinical diagnostic criteria for Parkinson's disease. Mov Disord.2015;30:1591-601. 
16. The Unified Parkinson's Disease Rating Scale (UPDRS): status and recommendations. Mov Disord.2003;18:738-50.

17. Goetz CG, Poewe W, Rascol O, Sampaio C, Stebbins GT, Counsell C, Giladi N, Holloway RG, Moore CG, Wenning GK et al. Movement Disorder Society Task Force report on the Hoehn and Yahr staging scale: status and recommendations. Mov Disord.2004;19:1020-8.

18. Chaudhuri KR, Martinez-Martin P, Brown RG, Sethi K, Stocchi F, Odin P, Ondo W, Abe K, Macphee G, Macmahon $\mathrm{D}$ et al. The metric properties of a novel non-motor symptoms scale for Parkinson's disease: Results from an international pilot study. Mov Disord.2007;22:1901-11.

19. Bose A, Beal MF. Mitochondrial dysfunction in Parkinson's disease. J Neurochem.2016;139 Suppl 1:216-31.

20. Tatton WG, Chalmers-Redman R, Brown D, Tatton N. Apoptosis in Parkinson's disease: signals for neuronal degradation. Ann Neurol.2003;53 Suppl 3:S61-70; discussion S-2.

21. Betarbet R, Sherer TB, Greenamyre JT. Ubiquitin-proteasome system and Parkinson's diseases. Exp Neurol.2005;191 Suppl 1:S17-27.

22. Puspita L, Chung SY, Shim JW. Oxidative stress and cellular pathologies in Parkinson's disease. Mol Brain. 2017;10:53.

23. Mosley RL, Hutter-Saunders JA, Stone DK, Gendelman HE. Inflammation and adaptive immunity in Parkinson's disease. Cold Spring Harb Perspect Med.2012;2:a009381.

24. Chen Y, Qi B, Xu W, Ma B, Li L, Chen Q, Qian W, Liu X, Qu H. Clinical correlation of peripheral CD4+cell subsets, their imbalance and Parkinson's disease. Mol Med Rep.2015;12:6105-11.

25. Stevens CH, Rowe D, Morel-Kopp MC, Orr C, Russell T, Ranola M, Ward C, Halliday GM. Reduced T helper and B lymphocytes in Parkinson's disease. J Neuroimmunol.2012;252:95-9.

26. Brodacki B, Staszewski J, Toczylowska B, Kozlowska E, Drela N, Chalimoniuk M, Stepien A. Serum interleukin (IL-2, IL-10, IL-6, IL-4), TNFalpha, and INFgamma concentrations are elevated in patients with atypical and idiopathic parkinsonism. Neurosci Lett.2008;441:158-62.

27. Kim R, Kim HJ, Kim A, Jang M, Kim A, Kim Y, Yoo D, Im JH, Choi JH, Jeon B. Peripheral blood inflammatory markers in early Parkinson's disease. J Clin Neurosci.2018;58:30-3.

28. Joshi N, Singh S. Updates on immunity and inflammation in Parkinson disease pathology.J Neurosci Res. 2018;96:379-90.

29. Schmitt N, Bentebibel SE, Ueno H. Phenotype and functions of memory Tfh cells in human blood. Trends Immunol.2014;35:436-42.

30. Chevalier N, Jarrossay D, Ho E, Avery DT, Ma CS, Yu D, Sallusto F, Tangye SG, Mackay CR. CXCR5 expressing human central memory CD4 T cells and their relevance for humoral immune responses. $J$ Immunol.2011;186:5556-68.

31. Morita R, Schmitt N, Bentebibel SE, Ranganathan R, Bourdery L, Zurawski G, Foucat E, Dullaers M, Oh $\mathrm{S}$, Sabzghabaei $\mathrm{N}$ et al. Human blood CXCR5(+)CD4(+) T cells are counterparts of T follicular cells and contain specific subsets that differentially support antibody secretion. Immunity.2011;34:108-21. 
32. Greisen SR, Rasmussen TK, Stengaard-Pedersen K, Hetland ML, Horslev-Petersen K, Hvid M, Deleuran B. Increased soluble programmed death-1 (SPD-1) is associated with disease activity and radiographic progression in early rheumatoid arthritis. Scand J Rheumatol.2014;43:101-8.

33. Weissferdt A, Fujimoto J, Kalhor N, Rodriguez J, Bassett R, Wistuba, II, Moran CA. Expression of PD-1 and PD-L1 in thymic epithelial neoplasms. Mod Pathol.2017;30:826-33.

34. Good-Jacobson KL, Szumilas CG, Chen L, Sharpe AH, Tomayko MM, Shlomchik MJ. PD-1 regulates germinal center B cell survival and the formation and affinity of long-lived plasma cells. Nat Immunol.2010;11:535-42.

35. Wing JB, Ise W, Kurosaki T, Sakaguchi S. Regulatory T cells control antigen-specific expansion of Tfh cell number and humoral immune responses via the coreceptor CTLA-4. Immunity.2014;41:1013-25.

36. Sage PT, Paterson AM, Lovitch SB, Sharpe AH. The coinhibitory receptor CTLA-4 controls B cell responses by modulating $T$ follicular helper, $T$ follicular regulatory, and $T$ regulatory cells. Immunity.2014;41:1026-39.

37. Ding L, Linsley PS, Huang LY, Germain RN, Shevach EM. IL-10 inhibits macrophage costimulatory activity by selectively inhibiting the up-regulation of B7 expression. J Immunol.1993;151:1224-34.

38. McCarron MJ, Marie JC. TGF-beta prevents T follicular helper cell accumulation and B cell autoreactivity. J Clin Invest.2014;124:4375-86.

39. Long D, Chen $Y, W u H$, Zhao M, Lu Q. Clinical significance and immunobiology of IL-21 in autoimmunity. J Autoimmun.2019;99:1-14.

\section{Figures}




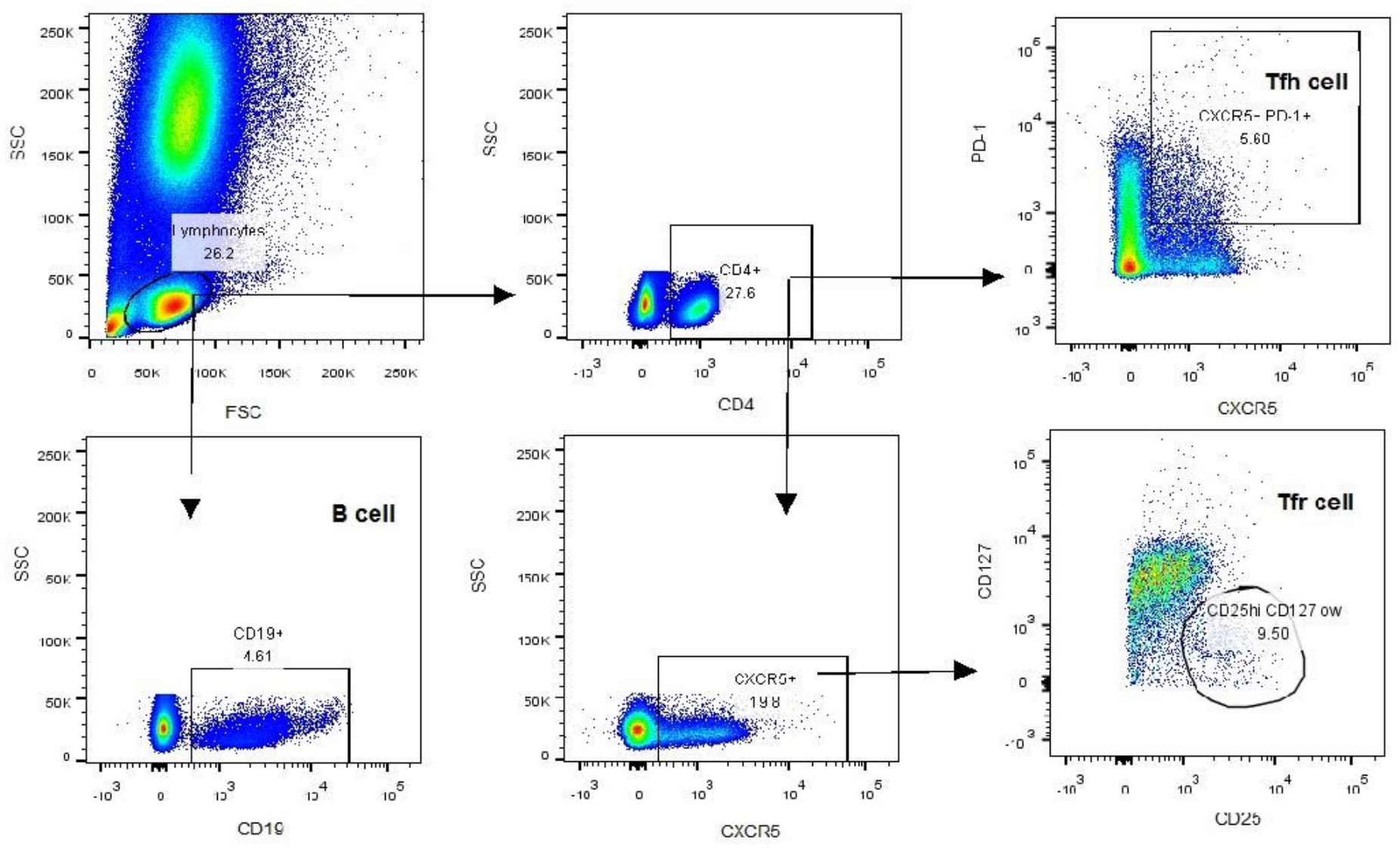

Fig .1 Flow cytometry analysis of circulating Th cells, Tfr cells and B cells

Figure 1

[Legend in image] 


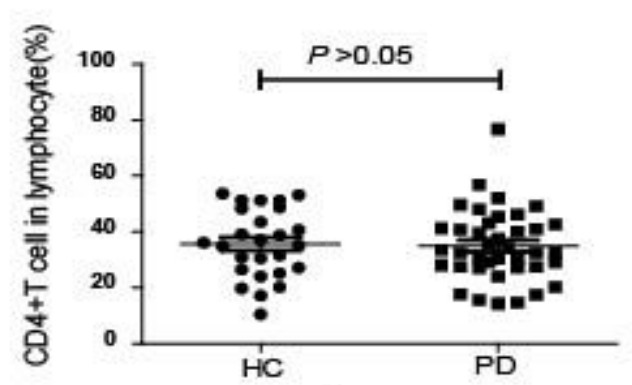

A

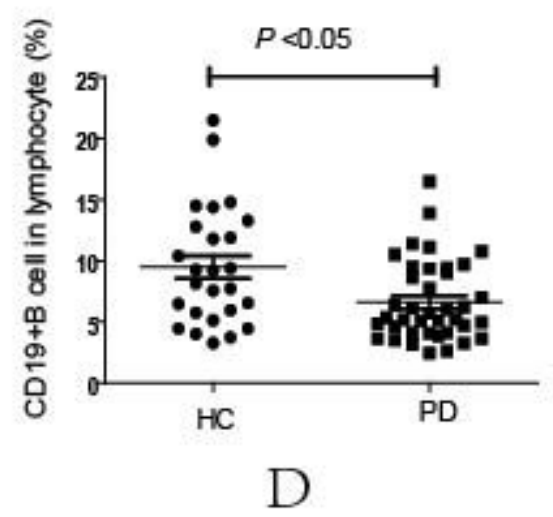

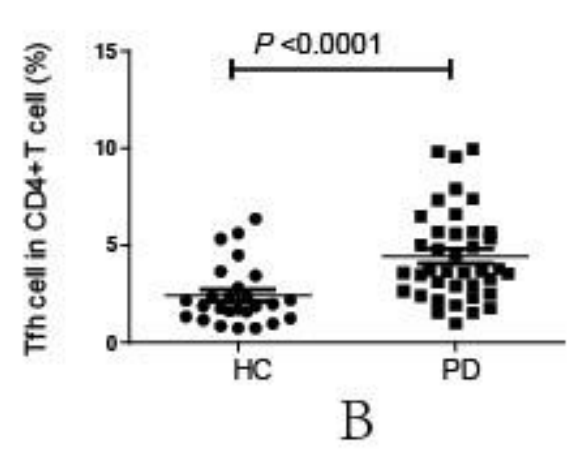

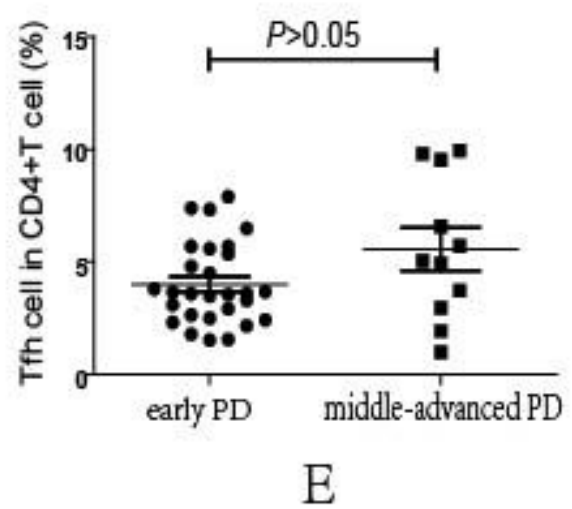

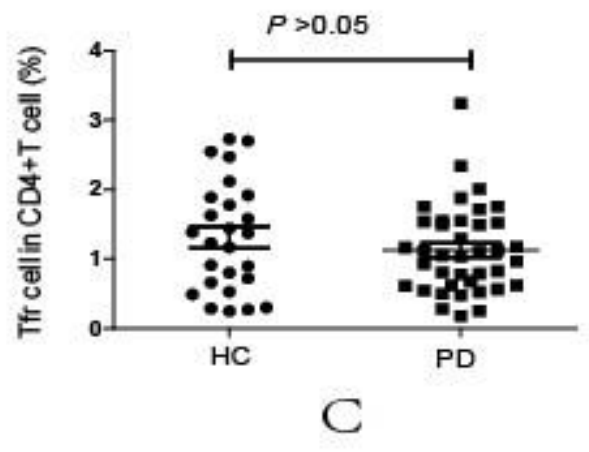

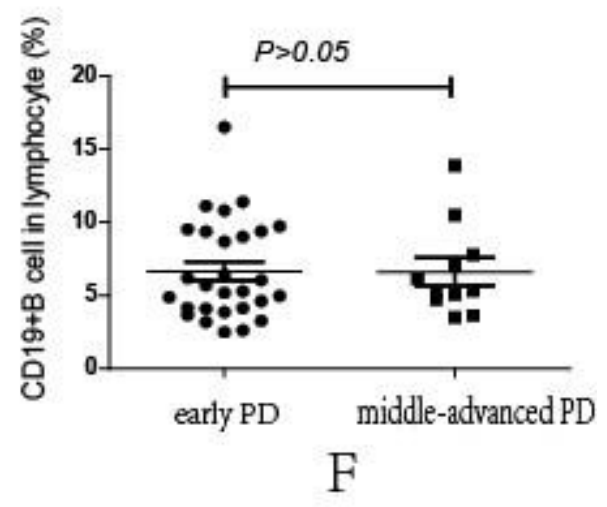

Fig. 2 The percentages of cTfh, cTfr and B cells in PD patients and HCs.

Figure 2

[Legend in image] 


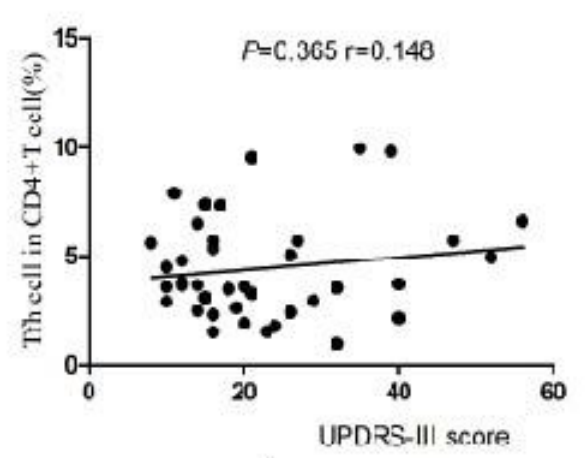

A

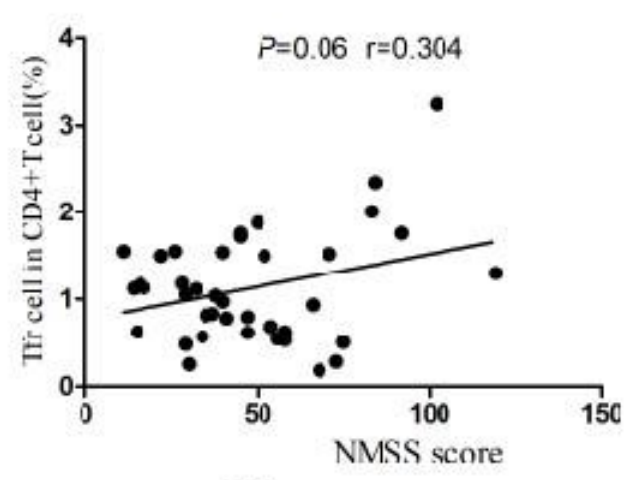

D
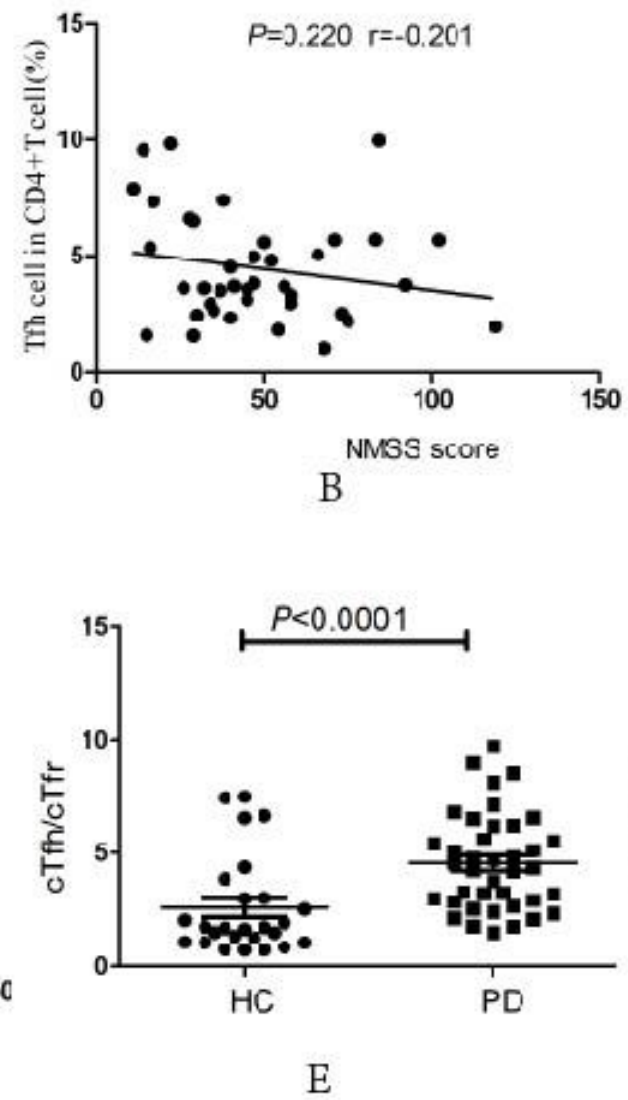
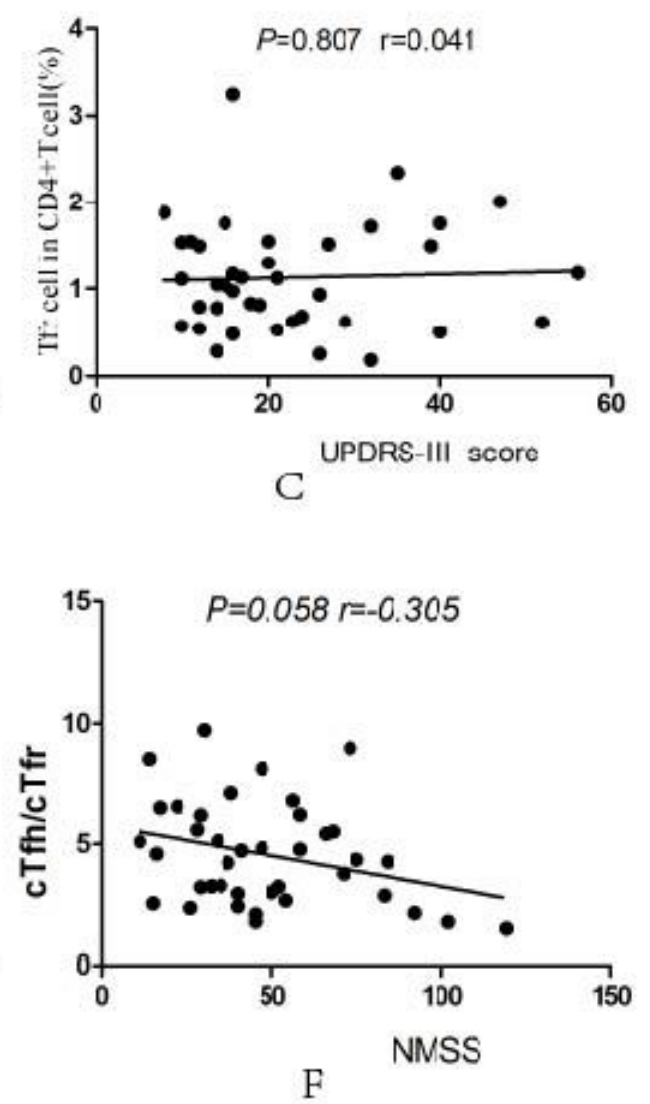

Fig. 3 Correlation analysis of $\mathrm{cTfh}, \mathrm{cTfr}$ or $\mathrm{cTfh} / \mathrm{cTfr}$ for clinical symptoms

Figure 3

[Legend in image] 


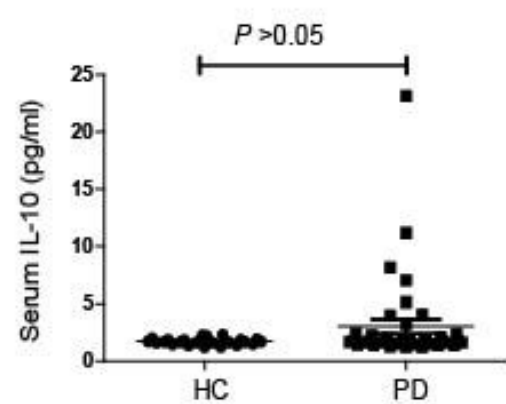

A

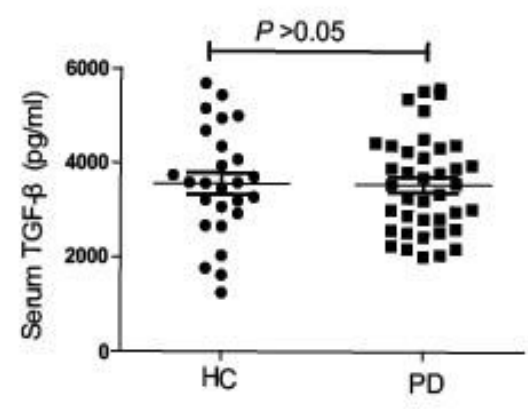

D

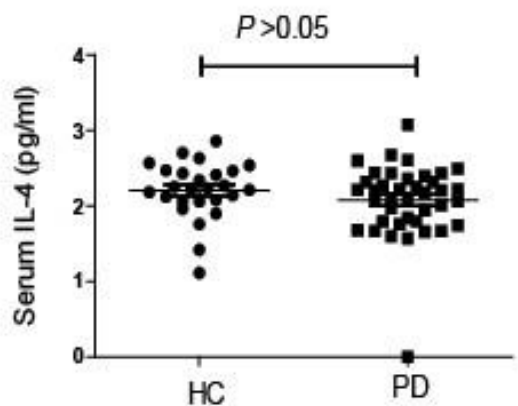

B

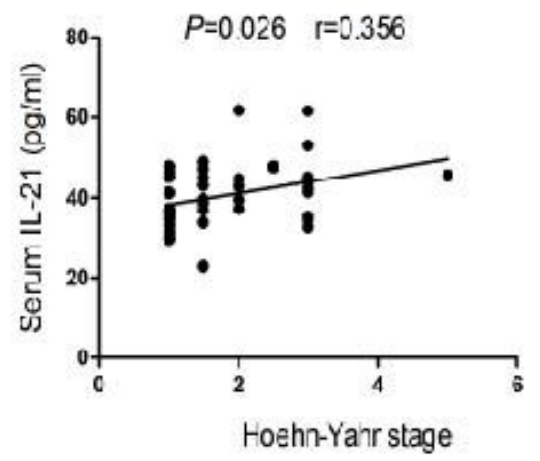

$\mathrm{E}$

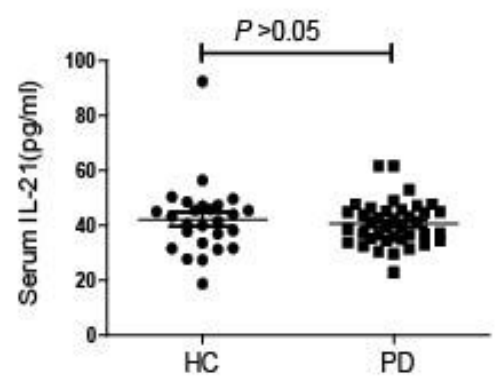

C

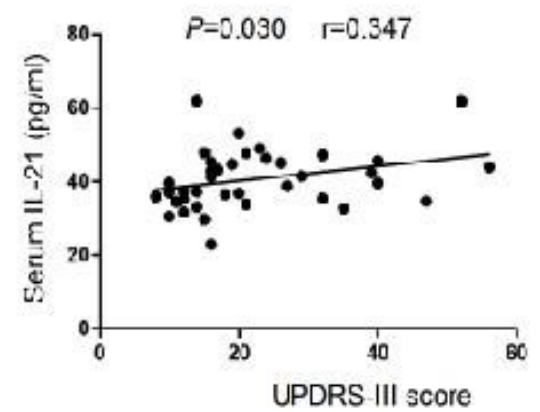

F

Fig. 4 Serum levels of $I L-4, I L-10, I L-21$ or TGF- 6 in PD patients and HCs, and correlation analysis of serum IL-21 levels with $\mathrm{H}-\mathrm{Y}$ stage and UPDRS-III score.

Figure 4

[Legend in image] 